\title{
PEMBINAAN NASIONALISME GURU PENDIDIKAN KEWARGANEGARAAN MELALUI PELATIHAN PROJECT CITIZEN DI KABUPATEN KUNINGAN
}

\author{
Encep Syarief Nurdin, Asep Dahliyana, Sri Wahyuni Tanshzil, Vini Agustiani Hadian \\ Universitas Pendidikan Indonesia
}

Email: encep.sn@upi.edu; asep dahly@upi.edu; sriwahyunitanshzil@upi.edu; viniagustiani87@upi.edu

\begin{abstract}
Abstrak Pendidikan Kewarganegaraan (PKn) merupakan mata pelajaran penting dan strategis dalam mengembangan misi membangun kesadaran dan kecakapan generasi muda agar memiliki karakter yang kuat sesuai dengan harapan negara yaitu nasionalisme (Pasal 37 UU No. 20 tahun 2003). Akan tetapi, praktik pembelajaran PKn tidak mendorong kemampuan siswa untuk berpikir kritis dan kreatif apalagi menginternalisasikan nilai nasionalisme. Dengan memperhatikan masalah tersebut, guru perlu dilatih dan diberdayakan dalam menguasai praktik penggunaan model pembelajaran PKn berbasis project yang dapat membina nasionalisme. Proses penelitian menggunakan pendekatan kuantitatif dan kualitatif dengan pola "the dominant-less dominat design". Pendekatan kuantitatif menggunakan survei dan pendekatan kualitatif sebagai pendalaman menggunakan wawancara. Populasi penelitian adalah guruguru PKn yang tergabung dalam MGMP Kabupaten Kuningan yang berjumlah 30 orang. Hasil penelitian menunjukkan bahwa guru PKn yang mengikuti program pelatihan Project Citizen berpengaruh terhadap pembinaan nasionalisme dengan indeks $87,67 \%$.

Kata kunci: $\quad$ pendidikan kewarganegaraan, project citizen, nasionalisme.
\end{abstract}

\section{PENDAHULUAN}

Mata Pelajaran PKn merupakan pelajaran wajib yang harus diikuti oleh setiap peserta didik mulai dari sekolah dasar sampai perguruan tinggi. Pada proses pembelajarannya, PKn bukan hanya memberikan penguasaan materi atau kognitif semata, melainkan terjadinya proses internalisasi nilai pada diri peserta didik dalam hal ini nasionalisme dan patriotism sebagaimana diamanatkan dalam Undang-Undang Nomor 20 Tahun 2003 tentang Sistem Pendidikan Nasaional. Akan tetapi, praktik pembelajaran PKn tidak mendorong kemampuan peserta didik untuk berpikir kritis dan kreatif apalagi menginternalisasikan nilai. Hal ini disebabkan model pembelajarannya cenderung berbentuk hafalan kognitif (Samsuri, 2010; Dianti, 2014; Winataputra dan Budimansyah, 2007) di mana metode pembelajaran yang digunakan cenderung monoton dengan hanya ceramah di depan kelas dan diskusi. Bahkan menurut David Kerr (1999:57) pelaksanaan PKn di Indonesia menunjukkan kategori minimal yang hanya mewadahi aspirasi tertentu, berbentuk pengajaran kewarganegaraan yang bersifat formal, terikat oleh isi, berorientasi pada pengetahuan, menitikberatkan pada proses pengajaran, dan hasilnya mudah diukur.
Oleh sebab itu, PKn dianggap kehilangan karakteristik akademisnya, karena model pembelajarannya dinilai lebih menekankan kepentingan rezim politik dengan materi yang tidak menarik dan formalistik. Proses pembelajaran tidak mendorong kemampuan peserta didik untuk berpikir kritis dan kreatif. Padahal PKn tidaklah cukup dimaknai sebagai mata pelajaran saja. Jauh lebih luas, PKn merupakan proses pendidikan untuk berbuat yang memiliki misi menumbuhkan potensi peserta didik agar memiliki civic knowledge, civic participation, dan civic responsibility. Untuk menumbuhkan potensi peserta didik agar memiliki civic knowledge, civic participation, dan civic responsibility (Dharma dan Siregar, 2015: 105).

Adapun metode pembelajaran yang harus dikembangkan PKn harus memiliki kriteria sebagai berikut: (1) proses pembelajarannya harus diorganisasikan dalam bentuk belajar sambil berbuat (learning by doing), belajar memecahkan masalah sosial (social problem solving learning), belajar melalui perlibatan sosial (socioparticipatory learning), dan belajar melalui interaksi sosial-kultural sesuai dengan konteks kehidupan masyarakat (Sumardjoko, 2013: 112); (2) pembelajaran PKn yang bermuatan nilai, bermakna, aktif, terpadu, mengundang 
kemampuan berfikir tingkat tinggi, demokratis, menyenangkan, efektif, efisien, kreatif, melalui belajar dengan bekerja sama (cooperative learning), dan mengundang aktivitas sosial (Maftuh, 2008: 143); (3) pembelajaran PKn harus dapat membangkitkan kesadaran akan dirinya atas tanggung jawab pribadi dan masyarakat (Sutrisno, 2015: 134); (4) pembelajaran PKn harus mampu mengkontribusi lahirnya manusia-manusia Indonesia yang mempunyai jiwa dan semangat yang tangguh dalam mendukung dan melaksanakan pembangunan bangsa dan negara sesuai dengan tujuan pendidikan nasional (Krisiatari, 2015: 2); (5) pembelajaran PKn harus dilaksanakan secara aktif dengan melakukan kegiatan (a) Mencari informasi dari berbagai sumber seperti buku teks, surat kabar, majalah, tokoh masyarakat, (b) membaca dan menelaah (studi pustaka), (c) mendiskusikan, (d) mempresentasikan, (e) memberi tanggapan, (f) memecahkan masalah atau kasus, (g) mengamati/mengobservasi, (h) mensimulasikan, (i) mendemonstrasikan, dan (j) memberi contoh (Cholisin, 2011: 6-7); (6) pembelajaran PKn harus mengembangkan keterampilan akademik dan sosial yang diperlukan agar seseorang dapat mengamalkan nilai-nilai yang dianut sehingga berprilaku konstruktif dan bermoral dalam masyarakat, yaitu berpikir kritis, berpikir kreatif, berkomunikasi secara jelas, menyimak, bertindak asertif, dan menemukan resolusi konflik (Widyaningsih, Zamroni, Zuchdi. 2014: 84); dan (7) proses pembelajaran harus menyuguhkan berbagai situasi bermasalah yang autentik dan bermakna kepada siswa, yang dapat berfungsi sebagai batu loncatan untuk investigasi dan penyelidikan (Arends, 2007:43).

Dengan demikian, hal yang harus dikembangkan mengarah pada pembelajaran berbasis project. Model pembelajaran yang tepat ialah melalui model pembelajaran Project Citizen. Hal ini disebabkan salah satu keunggulan model ini ialah mampu mengembangkan secara utuh tiga kompetensi kewarganegaraan seperti pengetahuan, keterampilan dan watak kewarganegaraan (Mariyani, 2017: 15). Project Citizen merupakan satu instructional treatment yang berbasis masalah untuk mengembangkan pengetahuan, kecakapan, dan watak kewarganegaraan demokratis yang memungkinkan dan mendorong keikutsertaan dalam pemerintahan dan masyarakat sipil. Tujuan Project Citizen adalah untuk memotivasi dan memberdayakan para siswa dalam menggunakan hak dan tanggung jawab kewarganegaraan yang demokratis melalui penelitian yang intensif mengenai masalah kebijakan publik di sekolah atau di masyarakat tempat mereka berinteraksi (Budimansyah, 2009:1-2). Hasil berbagai penelitian menunjukkan bahwa pelaksanaan Project Citizen dapat meningkatkan keterampilan berpikir kritis (Jayadiputra, 2015; Luqman, 2017). Namun, model ini tidak dilaksanakan untuk pembelajaran peserta didik, melainkan tenaga pendidik (guru) agar terjadi pembinaan nilai-nilai nasionalisme sebagaimana amanat UndangUndang Nomor 20 Tahun 2003 tentang Sistem Pendidikan Nasional. Hal ini dilakukan karena belum terdapat hasil penelitian yang menjelaskan secara utuh proses penggunaan model Project Citizen dengan nilai-nilai nasionalisme untuk guru. Selain itu menurut beberapa survey, guru sangat sedikit mendapatkan pelatihan yang betulbetul memengaruhi potensi guru menjadi profesional (Milson \& Mehlig, 2002; Guskey \& Passaro, 1994).

\section{METODE PENELITIAN}

Penelitian ini menggunakan metode campuran dengan pola "the dominant-less dominat design". Hal tersebut disebabkan pendekatan penelitian dengan kualitatif dan kuantitatif dapat digunakan dalam penelitian Pendidikan Kewarganegaraan. Pendekatan kuantitatif dijadikan sebagai pendekatan yang dominan sehinggga metode yang digunakan yaitu survey. Sementara, paradigma tambahan (kurang dominan) dengan pendekatan kualitatif untuk pendalaman. Pada tahap ini ditambahkan metode wawancara.

Teknik pengumpulan data dilakukan baik melalui kuesioner, wawancara, pengamatan secara langsung mengenai Pelatihan Model Pembelajaran Project Citizen Berbasis Pembinaan Nasionalisme dan Patriotisme bagi Guru Pendidikan Kewarganegaraan. Adapun responden yang diminta untuk mengisi kuesioner berjumlah 30 orang dan wawancara sebanyak 10 orang guru Pendidikan Kewarganegaraan Sekolah Menengah Kejuruan di Kabupaten Kuningan.

Dalam pembobotan jawaban dilakukan dengan pembagian sebagai berikut, $5=$ selalu, $4=$ sering, 3 = kadang-kadang, 2 = jarang, dan $1=$ tidak pernah. Adapun interval persentase nilai hasil jawaban dilakukan dengan penilaian berikut, $0-19,99=$ tidak berpengaruh, $20-39,99=$ kurang berpengaruh, 40 - 59,99 = cukup berpengaruh, $60-79,99=$ berpengaruh, dan $80-$ $100=$ sangat berpengaruh. Pengukuran dilakukan dengan menghitung jumlah $\%$ index dengan rumus Rumus Index \% = Total Skor $/$ Y x 100. 


\section{HASIL DAN PEMBAHASAN 3.1. Pelaksanaan Pembelajaran Pendidikan Kewarganegaraan Berbasis Projek}

Dalam pelaksanaan pembelajaran Pendidikan Kewarganegaraan berbasis project ditemukan beberapa hal yang berkaitan dengan penyesuaian situasi pembelajaran dengan tahaptahap pembelajaran, hambatan yang dihadapi serta manfaat yang dirasakan setelah mengikuti dan mengimplementasikan pembelajaran berbasis Project Citizen. Adapun hasil pada bagian ini didasarkan atas pengamatan lapangan dan berdasarkan hasil wawancara yang dilakukan dengan 10 perwakilan guru sasaran pelatihan yang dipilih secara acak.

Berkaitan dengan penyesuaian situasi dan tahap-tahap pelaksanaan pembelajaran, menurut informan "situasi pembelajaran menjadi lebih menarik dan tidak monoton. Selain itu, materi yang menjadi kompetensi dasar menjadi lebih mudah diaplikasikan dalam Project Citizen tersebut". Informan lain menyatakan bahwa "penyesuaian situasi pembelajaran lebih mudah dilakukan apabila menerapkan pembelajaran berbasis project". Bahkan salah satu informan menekankan bahwa "tahap-tahap pembelajaran berbasis project sangat sistematis, diawali dengan mencari masalah, mencari alternatif pemecahan masalah, dan membuat kesimpulan". Hal tersebut sejalan dengan penelitian yang dilakukan oleh Luqman (2017: 44) yang menyebutkan bahwa model pembelajaran Project Citizen dapat meningkatkan keterampilan berpikir kritis dan kreatif, yang dilakukan melalui enam langkah, yaitu: mengidentifikasi masalah; memilih masalah; mengumpulkan informasi; mengembangkan portofolio; menyajikan portofolio; dan refleksi pada pengalaman belajar. Tahap-tahap pembelajaran yang mudah diaplikasikan menjadikan pembelajan berbasis project lebih kondusif dan lebih hidup karena siswa diajak aktif terlibat dalam pembelajaran. Hal tersebut mendorong peserta pelatihan berkeyakinan bahwa pembelajaran PKn dengan Project Citizen mudah dilaksanakan dan menarik untuk siswa. Selain itu, peserta pelatihan menyatakan bahwa model ini sangat bagus untuk diterapkan dan langkah-langkahnya lebih mudah dipahami oleh guru. Dalam penuturannya, Budimansyah dan Sapriya (2012: 8) menjelaskan bahwa dalam Project Citizen telah mengimplementasikan empat pilar belajar yakni: (1) Learning to Know, yaitu suatu proses pembelajaran yang memungkinkan siswa menguasai teknik menemukan pengetahuan dan bukan semata-mata hanya memperoleh pengetahuan. (2) Learning to do, adalah pembelajaran untuk mencapai kemampuan untuk melaksanakan controlling, monitoring, maintening, designing, organizing. Belajar dengan melakukan sesuatu potensi yang konkret tidak hanya terbatas pada kemampuan mekanistis, melainkan juga meliputi kemampuan berkomunikasi, bekerjasama dengan orang lain serta mengelola dan mengatasi konflik. (3) Learning to live together adalah membekali kemampuan untuk hidup bersama dengan orang lain yang berbeda dengan penuh toleransi, saling pengertian dan tanpa prasangka. (4) Learning to be, adalah keberhasilan pembelajaran yang untuk mencapai tingkatan ini diperlukan dukungan keberhasilan dari pilar pertama, kedua, ketiga. Dengan penggunaan pilar-pilar ini, menurut Audigier (2000: 17) mengacu pada pengetahuan, sikap, nilai-nilai dan keterampilan yang diperlukan untuk berpartisipasi dalam kehidupan warga negara, serta mampu memainkan peran warga negara dan yang memungkinkan seseorang untuk menjadi warga yang aktif. Oleh karena itu, pengetahuan, keterampilan, nilai dan sikap harus dimasukkan dalam Kurikulum PKn tidak terpisah, tetapi terintegrasi dalam Kurikulum (Doğanay, 2012: 36)

Dalam hal ini, pendapat yang sama diungkapkan beberapa para ahli bahwa ruang lingkup Kurikulum PKn harus didasarkan pada tiga dimensi utama. Dimensi pertama, yaitu pengetahuan berisi sub kategori yang terdiri dari politik, sosial, budaya, ekonomi dan bentuk partisipasi. Dimensi kedua yang meliputi daerah afektif terdiri dari sub-kategori yaitu nilai-nilai, sikap dan disposisi. Dimensi terakhir yaitu keterampilan terdiri dari dua sub-kategori yaitu keterampilan umum dan kemampuan partisipasi (Doğanay, 2012: 31). Hal tersebut sejalan dengan "Visi - Kurikulum dan Pembelajaran PKn di Abad 21 - pada dasarnya terpusat pada pengembangan "learning intellegence" dalam dimensi-dimensi "Social, cultural. Political, economic, and technological intelligences..." (Winataputra dan Budimansyah 2012:3) yang merangsang warga negara untuk mau terlibat dalam fenomena yang didasari kombinasi kompleks pengetahuan, keterampilan, pemahaman, nilai-nilai, sikap dan keinginan yang menyebabkan efektif, dan diwujudkan dalam tindakan pada domain tertentu yang diperlukan untuk partisipasi dalam kehidupan sipil dan politik, sehingga hal tersebut mampu memainkan peran warga negara menjadi warga aktif (Print, 2013; Print dan Lange, 2012).

Namun demikian, masih terdapat hambatan dalam pelaksanaan Project Citizen secara umum. Hambatan yang dirasakan oleh peserta dalam menerapkan pembelajaran ini 
adalah perlu adanya dukungan sistem agar setiap kebutuhan dalam pembelajaran dapat dipenuhi dengan baik. Hambatan yang dirasakan peserta lain yaitu lebih berat dan berasal dari luar siswa, ia menuturkan bahwa perkembangan IPTEK berpengaruh kuat pada rasa nasionalisme warga negara. Sehingga perlu kekuatan lebih untuk memahamkan kembali dan melembagakannya dalam setiap pribadi warga negara.

Hambatan yang dirasakan oleh peserta lain dalam menanamkan rasa nasionalisme adalah masalah waktu. Butuh kesabaran dan keyakinan kuat karena proses penanaman nilai harus dilakukan dengan bertahap. Hal yang sama juga diungkapkan oleh peserta lain yang menyatakan bahwa "penyesuaian waktu sangat berpengaruh terhadap pembelajaran ini. Siswa SMK memiliki kemampuan yang berbeda sehingga waktu yang dibutuhkan dalam penanaman nilai harus disesuaikan dengan kemampuan siswa".

Selain waktu, peserta lain menjelaskan bahwa "intensitas interaksi dan komunikasi dengan peserta didik juga mempengaruhi penanaman rasa nasionalisme dan patriotisme. Kurangnya komunikasi mengakibatkan terhambatnya proses penanaman nilai. Hambatan lainnya adalah kesulitan dalam menentukan data dan fakta apabila isu yang diambil memiliki informasi yang terbatas". Terdapatnya kesulitan data ini membuat pembelajaran menjadi terhambat karena siswa dihadapkan dengan kebingungan dalam mencari informasi yang relevan dengan isu yang mereka pilih.

Namun demikian, dalam menanamkan nasionalisme pada diri peserta didik harus melakukannya penuh dengan demokratis, karena dengan suasana demokratis sekolah dapatt mengembangkan karakter peserta didik tersebut (Althof \& Berkowitz, 2006; Milson \& Mehlig, 2002). Hasil penelitian Van Hees (2011: 56) menyarankan bahwa guru harus merubah pengetahuan dan praktik mereka, serta perhatian eksplisit mereka untuk menciptakan kondisi optimal untuk interaksi dan ekspresi peserta didik, yang penting dalam membuat perbedaan dalam hasil peserta didik.

Adapun manfaat yang dirasakan oleh guru sasaran terangkum dalam beberapa poin berikut: (1) mengasah kreativitas guru dalam berinovasi untuk menentukan pembelajaran yang bervariasi khususnya dalam menerapkan sikap nasionalisme; (2) menambah kompetensi guru sebagai penunjang pelaksanaan pembelajaran di sekolah masing-masing; (3) pembelajaran menjadi lebih menarik, banyak menggali potensi siswa dan menentuan evaluasi mudah dilakukan; (4) membuka pemikiran bahwa pembelajaran bukan hanya sebatas menyampaikan materi, melainkan mencari cara agar minat siswa dalam belajar semakin meningkat; dan (5) menambah wawasan guru dalam penerapan model serta menguatkan rasa nasionalisme.

\subsection{Pengaruh Pembelajaran Project Citizen terhadap Nilai-Nilai Nasionalisme Guru}

Pada dasarnya pembelajaran model Project Citizen lebih menonjolkan kepada strategi upaya memahamkan siswa dengan dasar-dasar pengetahuan, bagaimana warga negara harus mengambil tanggung jawab kewarganegaraan (Samsuri, 2011: 4). Oleh karena model Project Citizen, menurut Vontz \& Patrick (2000: 6) akan memberikan setiap orang kesempatan untuk berpartisipasi dalam pemerintahan dan masyarakat dengan cara berlatih berpikir kritis, dialog, debat, negosiasi, kerja sama, kesopanan, toleransi, pengambilan keputusan, dan tindakan sipil untuk kebaikan bersama. Melalui keikutsertaan mereka dalam Project Citizen, para siswa memiliki satu kesempatan untuk mengembangkan berbagai watak kewarganegaraan dari kewarganegaraan demokrasi seperti nilai politik, kepentingan politik, toleransi politik, komitmen terhadap perlaksanaan hak kewarganegaraan demokrasi, komitmen terhadap tanggung jawab kewarganegaraan demokrasi, komitmen terhadap konstitusionalisme dan kecenderungan untuk berpartisipasi secara politik (Budimansyah 2009:21). Oleh sebab itu, guru tidak hanya menggunakan satu sumber, tetapi mengajak peserta didik menggunakan berbagai sumber (Laksono, 2016: 30).

Alasan melakukan pengabdian dengan melaksanakan pelatihan Project Citizen terhadap guru bahwa "guru merupakan pusat pendidikan karakter" (Anderson, 2000: 139). Di mana pendidikan karakter akan lebih efektif dalam kondisi mendorong peserta didik dengan karakter baik yang juga "dilegitimasi, dimodelkan, dan diperkuat oleh sekolah dan guru" (Romanowski, 2005: 17). Oleh sebab itu, guru harus diberikan pelatihan bagaimana membina nasionalisme sebelum menginternalisasikannya kembali kepada peserta didik. Oleh sebab menurut beberapa survey guru sangat sedikit mendapatkan pelatihan yang betul-betul memengaruhi potensi guru menjadi professional (Milson \& Mehlig, 2002; Guskey \& Passaro, 1994). Lickona (1992: 11) mengamati, pendidikan karakter jauh lebih rumit daripada mengajar matematika atau membaca. Hal itu membutuhkan pertumbuhan pribadi 
sekaligus pengembangan keterampilan. Namun, para guru biasanya menerima hampir tidak ada pelatihan pra-layanan atau in-service dalam aspek moral keahlian mereka. Banyak guru tidak merasa nyaman atau kompeten dalam domain nilai.

Menurut Jones, Ryan, dan Bohlin (1998: 11), sedikit perhatian ilmiah telah diberikan pada apa yang saat ini sedang dilakukan pada tingkat persiapan guru untuk melengkapi guru masa depan dengan keterampilan dan pengetahuan yang mereka butuhkan untuk bekerja secara efektif sebagai "pendidik karakter". Namun demikian, dalam pelatihan Project Citizen ini ditemukan bahwa berdasarkan hasil pengisian kuesioner pengaruh pelatihan berbasis Project Citizen pada penguatan nasionalisme guru sebagai berikut.

Tabel 1.

Pengaruh Metode Pembelajaran Project Citizen terhadap Nilai-nilai Nasionalisme Guru

\begin{tabular}{llll}
\hline No. & Indikator Nasionalisme & $(\%)$ & \multicolumn{1}{c}{ Keterangan } \\
\hline 1 & Menjaga dan melindungi Negara & 84.83 & Sangat Berpenganuh \\
\hline 2 & Sikap rela berkorban/ patriotisme & 87.17 & Sangat berpenganuh \\
\hline 3 & Indonesia bersatu & 87.00 & Sangat berpenganuh \\
\hline 4 & Melestarkikan budaya Indonesia & 85.00 & Sangat berpenganh \\
\hline 5 & Cinta tanah air & 89.67 & Sangat berpenganuh \\
\hline 6 & Bangga berbanggsa Indonesia & 90.33 & Sangat berpenganuh \\
\hline 7 & Menjunjung tinggi nilai kemanusiaan & 89.67 & Sangat berpenganuh \\
\hline & TOTAL persentase index & 87.67 & Sangat berpenganh \\
\hline
\end{tabular}

Dilihat dari hasil tersebut dapat diketahui bahwa dilihat dari hasil total persentase index jawaban, angka hasil kuesioner dari 30 guru sasaran menunjukkan angka $87,67 \%$ yang berarti jika diterjemahkan melalui interval persentase, angkat tersebut berarti bahwa pelatihan pembelajaran PPKn berbasis Project Citizen sangat berpengaruh terhadap penguatan nasionalisme guru. Jika dilihat dari persentase masing-masing indikator, angka tertinggi $(90,33 \%)$ ditunjukkan pada indikator ke enam yaitu bangga berbangsa Indonesia. Adapun yang terendah ditunjukkan oleh indikator pertama $(84.83 \%)$ yaitu menjaga dan melindungi negara.

Meskipun begitu, tujuh indikator yang diuji dalam kuesioner menunjukkan index persentase sangat berpengaruh dengan rincian persentase sebagai berikut: (1) menjaga dan melindungi negara memiliki jumlah $84,83 \%$; (2) sikap rela berkorban dan patriotisme berjumlah $87,17 \%$; (3) Indonesia bersatu berjumlah $87 \%$; (4) melestarikan budaya Indonesia berjumlah $85 \%$; (5) cinta tanah air berjumlah $89,67 \%$; (6) bangga berbangsa Indonesia berjumlah $90,33 \%$; dan (7) menjunjung tinggi nilai kemanusiaan berjumlah $89,67 \%$.

Dari hasil tersebut diketahui bahwa pelatihan yang dilaksanakan guna mengembangkan model pembelajaran PPKn berbasis Project Citizen memberikan dampak yang signifikan terhadap penguatan nasionalisme guru sasaran pelatihan. Hal tersebut ditunjukkan oleh hasil penghitungan yang semuanya menunjukkan bahwa pelatihan tersebut mengembangkan setiap indikator yang dimiliki oleh guru sebagai sasaran pelatihan. Dengan demikian pengaruh secara keseluruhan sangat ditunjukkan dengan sangat signifikan karena hasil keseluruhan menunjukkan 87,67\%.

\section{KESIMPULAN}

Tenaga pendidik dalam hal ini guru selalu akan menjadi korban dari kurikulum yang di kembangkan oleh suatu kebijakan pendidikan. Mereka dipaksa untuk menguasai suatu ketentuan yang ada dalam kebijakan tersebut. Namun, sedikit sekali peluang atau proses pelatihan yang diberikan kepada guru untuk menjadikannya lebih profesional. Adanya kegiatan pengabdian ini, bertujuan agar guru PKn di wilayah Kabupaten Kuningan memahami bahwa salah satu tujuan penyelenggaraan PKn yaitu untuk pembinaan rasa nasionalisme peserta didik. Oleh sebab itu, perlu dilakukan pembinaan melalui pelatihan Project Citizen, karena guru merupakan pusat pendidikan karakter di sekolah yang harus dibekali keterampilan memadai dalam menggunakan metode pembelajaran. Adapun hasil yang didapatkan dengan pelatihan tersebut bahwa guru PKn yang mengikuti program Project Citizen sangat berpengaruh terhadap pembinaan nasionalisme dengan indeks $87,67 \%$.

\section{REFERENSI}

Althof, W, Berkowitz, MW. (2006). Moral Education and Character Education: The Realtionship and Roles in Citizenship Education. Journal of Moral Education. 35, (4), 495-518.

Anderson, D. R. (2000). Character education: Who is responsible? Journal of Instructional Psychology, 27(3), 139.

Arends, R. I. (2007). Learning to Teach Belajar untuk Mengajar. Yogyakarta: Pustaka Belajar.

Audigier, F. (2000). Basic concepts and core competencies for education for democratic citizenship. Strasbourg: Council of Europe.

Budimansyah, D (2010). Penguatan Pendidikan Karakter Melalui Pendidikan Kewarganegaraan. Bandung: Widya Akasara Press

Budimansyah, D dan Sapriya. (2012). DimensiDimensi Praktik Pendidikan Karakter. 
Bandung: Program Studi Pendidikan Kewarganegaraan SPS UPI Bandung

Budimansyah, D. (2008). Pembelajaran Pendidikan Kesadaran Multikultural. Bandung: Grasendo

Budimansyah, D. (2009). Inovasi Pembelajaran Project Citizen. Program Studi Kewarganegaraan, UPI.

Cholisin. (2011). Pengembangan Karakter Dalam Materi Pembelajaran Pkn. Yogyakarta: Universitas Negeri Yogyakarta.

Dharma, S dan Siregar, R. (2015). Membangun Pengalaman Belajar Kewarganegaraan melalui Model Pembelajaran Project Citizen pada Siswa. Jurnal Pendidikan Ilmu-Ilmu Sosial. 7 (1), 100-106.

Dianti, P. (2014). Integrasi Pendidikan Karakter dalam Pembelajaran Pendidikan Kewarganegraan untuk Mengembangkan Karakter Siswa. Jurnal Pendidikan Ilmu Sosial. 23 (1). 58-68.

Doğanay, A. (2012). A curriculum framework for active democratic citizenship education. In M. Print \& D. Lange (Eds.), Schools, Curriculum and Civic Education for Building Democratic Citizens (pp. 1939). Roterdam, Boston, Taipe: Sense Publisher.

Guskey, T. R., \& Passaro, P. D. (1994). Teacher Efficacy: A study of Construct Dimensions. American Educational Research Journal, 31(3), 627-643.

Jayadiputra, E. (2015). Model Project Citizen dalam Meningkatkan Keterampilan Berpikir Siswa. Jurnal Ilmiah CISOC: Kajian Rumpun Pendidikan Ilmu Sosial. 2 (1), 11-20.

Jones, E. N., Ryan, K., \& Bohlin, K. (1998). Character Education and Teacher Education: How are prospective teachers being prepared to foster good character in students? Action in Teacher Education, 20, 11-28.

Kerr, D. (1999). Citizenship Education: an International Comparison. London: Quality Curriculum Association.

Krisiantari, P. et.al. (2015). Pengaruh Model Pembelajaran Rsolusi Konflik terhadap Motivasi Belajar PKn Siswa Kels V Semester Genap Di SD Gugus VIII KEcamatan Banjar Kabupaten Buleleng Tahun Pelajaran 2014/2015. E-Journal PGSD Universitas Pendidikan Ganesha. 3 (1). 1-11.

Laksono, K.,dkk. (2016). Manual Pendukung Pelaksanaan Gerakan Literasi Sekolah untuk Jenjang Sekolah Menengah Pertama. Jakarta: Kementerian Pendidikan dan Kebudayaan.
Lickona, T. (1992). Educating For Character How Our Schools Can Teach Respect and Responsibility. New York: Bantam Books.

Luqman. (2017). Penerapan Model Pembelajaran Project Citizen untuk Meningkatkan Keterampilan Berpikir Kritis dan Kreatif Siswa. Jurnal Ilmu Pendidikan. 2 (1), 4459

Maftuh, B. (2008). Internalisasi Nilai-Nilai Pancasila dan Nasionalisme melalui Pendiidkan Kewarganegaraan. Jurnal Educationist. 2 (2). 134-144.

Maryani. (2017). Strategi Pembentukan Kewarganegaraan Ekologis. Prosiding Konferensi Nasional Kewarganegaraan III. 11 November 2017 di Universitas Ahmad Dahlan, Yogyakarta. Halaman 10-17.

Milson, A.J \& Mehlig, L.M. (2002). "Elementary School Teachers Sense of Efficacy for Character Education". The Journal of Education Research. 96 (1), 47-53.

Milson, A.J \& Mehlig, L.M. (2002). "Elementary School Teachers Sense of Efficacy for Character Education". The Journal of Education Research. 96 (1), 47-53.

Print, M. (2013). Competencies for democratic citizenship in europe. In M. Print \& D. Lange (Eds.), Civic Education and Competences for Engaging Citizens in Democracies (37-50). Roterdam, Boston, Taipe: Sense Publishers.

Print, M., \& Lange, D. (Eds.). (2012). Schools, curriculum and civic education for building democratic citizens. Roterdam, Boston, Taipe: Sense Publishers. http://doi.org/10.1007/978-94-6209-1672

Romanowski, M. H. (2005). Through the eyes of teachers: High school teachers' experiences with cha-racter education. American Secondary Education, 34(1), 6-23.

Samsuri. (2010). "Pembentukan Karakter Warga Negara Demokratis dalam Politik Pendidikan Indonesia Periode Orde Baru Hingga Era Reformasi”. Dalam MGMP PKn Kab.Sleman. Sleman Press.

Samsuri. (2011). Model pembelajaran Pendidikan Kewarganegaraan untuk membangun komperensi warga negara. In Kuliah Umum di Program Studi Pendidikan Pancasila dan Kewarganegaraan (PPKn) FKIP Universitas Ahmad Dahlan 9 Mei 2011 (pp. 1-13). Yogyakrta.

Sumardjoko, B. (2013). Revitalisasi Nilai-Nilai Pancasila melalui Pembelajaran PKn 
Berbasis Kearifan Lokal untuk Penguatan Karakter dan Jati Diri Bangsa. Jurnal Varia Pendidikan. 25 (2). 110123.

Sutrisno, E. (2015). Internalisasi Nilai-Nilai Pancasila dalam Pembelajaran Pendidikan Kewarganegaraan sebagai Upaya Kesadaran terhadap Hukum Di Lembaga Pendidikan Islam. Jurnal Review Pendidikan Islam. 2 (1). 117136.

Undang-Undang Nomor 20 tahun 2003 tentang Sistem Pendidikan Nasional.

Van Hees, J. (2011). The Expressive Realities of 5- and 6-year-olds in Low Socioeconomic schools. Set: Research Information for Teachers [Wellington] 3, 47-59.

Vontz, T. S., Metcalf, K. K., \& Patrick, J. J. (2000). "Project Citizen" and the civic development of adolescent students in Indiana, Latvia, and Lithuania. Bloomington IN: ERIC Clearinghouse for Social Studies.

Widyaningsih, T.S.,Zamroni, dan Zuchdi, D. (2014). Internalisiasi dan Aktualisasi Nilai-Nilai Karakter pada Siswa SMP dalam Perspektif Fenomenologis (Studi Kasus di SMP 2 Bantul). Jurnal Pembangunan Pendidikan: Fondasi dan Aplikasi. 2 (2). 181-195.

Winataputra, U.S dan Dasim Budimansyah. (2007). Civic Education: Konteks, Landasan, Bahan Ajar dan Kultur Kelas. Bandung: Prodi PKn SPS UPI. 